\title{
Using free tools to support the BIM coordination process into SMEs
}

\author{
V. Muñoz \& Y. Arayici \\ School of the Built Environment, University of Salford, UK
}

\begin{abstract}
Building Information Modelling (BIM) has proved to be a useful methodology for the AEC industry, bringing into it a large number of benefits. Despite all these advantages, BIM faces barriers that hinder its broad implementation within AEC companies. The largest barrier pointed out by the literature is the high initial investment (hardware, software and training). As a result, Small and Medium Enterprises (SMEs) have not been involved in the process and the integration that BIM should incorporate into a project is undermined because of the impossibility of each party to work with this technology.

This research proposes to use free tools during the coordination process to support those SMEs unable to invest in software or training. To achieve this goal, it will be necessary to review the software available in the market, then the most suitable tools will be chosen for the coordination process, and finally a workflow to provide support will be proposed. The proposed workflow had proved to be good enough to be used by SMEs, however it is necessary to follow the sequence indicated in order to avoid interoperability issues.

Keywords: building information modelling, BIM coordination, SMEs, free software.
\end{abstract}

\section{Introduction}

Early adopters of BIM technologies have reported great benefits from its implementation at company and project level. Despite the benefits, the SMEs are late with the BIM implementation because of the large barrier that funding software, hardware and skilled staff means for this kind of companies. The difficulty of these companies to implement BIM is preoccupying considering that some governments will start to demand the use of this methodology in their 
projects. Considering further the large amount of work positions that SMEs generate and that could be threatened for this delay in the BIM adoption, is easy to figure out why it is necessary to help to SMEs in their implementation process.

Under this scenario, is interesting to note a recent change in the commercial strategy between software developers to offer completely free of charge tools, then the benefits for these companies is associated with the sale of products such as plugins, customizations and consulting.

Because of the feature that free software has (free of charge and simple interface) it could help to overcome some barriers. Unfortunately the literature has been unaware in these software and how useful they may be. In this context, this research aims to awareness about the use of these tools in during the BIM coordination process.

\section{Literature review}

\subsection{Barriers for BIM implementation}

The literature identifies some elements that hinder BIM adoption into companies. These barriers are cross the project, affecting each actor from owners to contractors [1].

Authors such as Eastman et al. [2], Deutsch [3] and Elvin [4] agree pointing out to the cost and lack of training as important entry barriers to adopt BIM into companies. In this sense the National Report 2015 identifies to the lack of training and cost as the most important barriers with $67 \%$ and $56 \%$ of preferences respectively [5]. Then any firm who wants to implement BIM needs to consider investing in infrastructure (hardware, software and network) and staff training [6].

Nonetheless, BIM tools are not cheap with a range of prices from $\$ 5,000$ up to $\$ 11,000$. In addition to the software cost, it is necessary to keep on mind an annual subscription for updating the software, then this investment will not be done just one time [7].

On the other hand, finding trained staff is very difficult $[4,8]$ because of the high demand they have [7]. Indeed, Smith and Tardif [9] say that the demand for highly skilled professionals will keep growing in upcoming years and the institutions of higher learning will be unable to satisfy this demand in the short time. A solution to this lack of staff could be to form in house professionals, nevertheless to do this may be more expensive than investing in infrastructure, besides it is needs to consider a "learning curve cost" in which the staff is learning to use the software, then the initial productivity will be reduced [2].

\subsection{Workflow and collaboration issues}

As previously mentioned, there are specific reasons that are avoiding the BIM adoption to some actors. This inability to be involved in the process is undermining essential premises supported by BIM process such as workflow and collaboration across lifecycle project [4]. 
A non BIM user will affect the communication into the project, making it slow with long feedback cycles [10]. Nonetheless, the success of BIM implementation depends on recognizing that the data generated by anyone will be useful to someone else to carry out some activity following some requirements [9], then the BIM user will need to communicate their ideas and problems to these non BIM users. Currently, the only way to allow this communication is through traditional means such as drawings, meetings and spreadsheets or web based tools to request for information (RFI) [2].

\subsection{BIM for Small and Medium Enterprises (SMEs)}

In this scenario with barriers hindering the BIM adoption to some companies is that arises the concern about how the SMEs will deal with this challenge. Even though the average European enterprise is formed by less than six people [11], it is important to pay attention in this type of companies because they play a central role in any economy, being the major source of innovation and employment. In the European case, they represent $99 \%$ of all enterprises and provide around 75 million jobs $[11,12]$.

While SMEs are important for the economic growth of any country, they have difficulties in obtaining capital then the access to technologies or innovation is reduced [11]. Despite the economic factor may be discourage the BIM implementation into SMEs, it is important that these companies recognize the benefits that this methodology will bring into their projects. BIM is a differentiator element that gives the chance to any company to compete against large ones offering added value, less risk, and better outcomes [13].

\subsection{Using free software}

In this unfavourable scenario, with economical and staff barriers, the use of free software seems to overcome these barriers and demonstrate the BIM benefits to those firms who hesitant to invest in software or training. The main features present in this type of software are: easy to use, customizable and free of charge or lower cost [14].

The free software concept does not mean "free of charge", then will need to explain this term in order to clear up which type of software will used in this research. The free software may be classified based on three characteristics: cost, source code distribution and rules governing use, then is possible to find four categories of software [15]:

- Public domain software: the author/owner has given up all his property rights of the software. There is no copyright protecting public domain software.

- Free/open source software: the "free" concept refers to the freedom of the user to run, copy, distribute, study, change, and improve the software. This software is free of charge, besides the source code is available to modify.

- Freeware: this software is free of charge, can be shared and used for any reason. The difference with free/open source software is that freeware's source code is not available for users, then it is not possible to modify according user's needs. 
- Shareware: this is another free of charge software, normally this software is free for a period of time and after that the user must to pay in order to keep using the software.

For this paper, the term free will be referred to FREE OF CHARGE therefore it will considerate the use of free/open software and/or freeware.

\section{Methodology}

The methodology used to demonstrate how useful may be free software in the coordination process will require identifying and classifying the software available, then choosing the suitable tools for the process and finally to propose a workflow.

\subsection{Identifying and classifying software}

In the market is possible to find different free software that have a direct relationship with BIM workflows. In a review process eight different software have been found. From these software have been excluded any free cloud service because of any server applied to BIM technologies needs to fulfil some requirements beyond the scope of this research.

The applications identified have been grouped by common features, then the software is classified in:

- Viewer/checker: in this category are included any software able to read a BIM model to carry out any kind of analysis. The applications in this section are: Tekla BIMsight, DDS CAD, xBIM Xplorer, Navisworks Freedom, BIM Vision and Solibri Model Viewer.

- $\quad$ BCF tools: in this category is considered BCFier, this tool allows to read and write Building Collaboration Format (BCF) files.

- IFC optimizer: In this category is found it just one tool, Solibri IFC optimizer, to optimize IFC files eliminating redundant data and reducing the size file up to $95 \%$ of the original size.

\subsection{Selecting a viewer/checker tool}

As previously had been discussed there are six different viewers available in the market then will be necessary to select one to include in the workflow to propose in this research.

Below criteria will be used to select a viewer/checker tool:

- Features: it refers to different tools or uses that the software has

- Interoperability: different formats supported by software to allow the information exchange between different applications

- Usability: it is the ease of use and learning a software

Table 1 summarizes the characteristics of each viewer, in it is possible to see that Tekla BIMsight has a large number of features, high interoperability and usability, followed by DDS CAD. While in the opposite corner are Navisworks Freedom and XBIM Xplorer. The case of BIM Vision is interesting, this software 
has the feature to compare graphically the difference between two model versions, then using this tool will be possible to identify which elements have being added, deleted or modified. Besides this comparative process is not carry out just between geometries, it includes the data embedded in each element.

Table 1: Main characteristics of BIM viewers.

\begin{tabular}{|c|c|c|c|c|c|c|}
\hline & $\begin{array}{l}\stackrel{\theta}{\circlearrowright} \\
\tilde{D} \\
\hat{0}\end{array}$ & 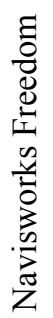 & 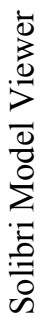 & 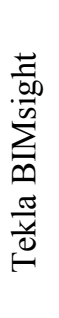 & 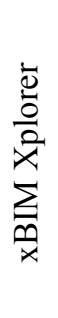 & 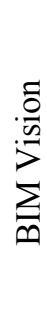 \\
\hline \multicolumn{7}{|l|}{ Features } \\
\hline Soft clashes & & & & $\mathrm{x}$ & & \\
\hline Hard clashes & $\mathrm{x}$ & & & $\mathrm{x}$ & & \\
\hline Management of clashes & & & & $\mathrm{x}$ & & \\
\hline Mark up & $\mathrm{x}$ & & $\mathrm{x}$ & $\mathrm{x}$ & & $\mathrm{x}$ \\
\hline Attach documents & & & & $\mathrm{x}$ & & \\
\hline Different visualizations & $\mathrm{x}$ & $\mathrm{x}$ & $\mathrm{x}$ & $\mathrm{x}$ & & $\mathrm{x}$ \\
\hline Multiple models & $\mathrm{x}$ & & & $\mathrm{x}$ & $\mathrm{x}$ & \\
\hline Save changes & $\mathrm{x}$ & & $\mathrm{x}$ & $\mathrm{x}$ & $\mathrm{x}$ & $\mathrm{x}$ \\
\hline Measure tool & $\mathrm{X}$ & $\mathrm{x}$ & $\mathrm{x}$ & $\mathrm{x}$ & & $\mathrm{x}$ \\
\hline \multicolumn{7}{|l|}{$4 \mathrm{D}$} \\
\hline Management colours & $\mathrm{x}$ & $\mathrm{x}$ & & $\mathrm{x}$ & & \\
\hline Model comparison & & & & & & $\mathrm{x}$ \\
\hline
\end{tabular}

\begin{tabular}{|r|c|c|c|c|c|c|}
\hline Interoperability \\
\hline IFC & $\mathrm{x}$ & & $\mathrm{x}$ & $\mathrm{x}$ & $\mathrm{x}$ & $\mathrm{x}$ \\
\hline IFCzip & $\mathrm{x}$ & & $\mathrm{x}$ & $\mathrm{x}$ & $\mathrm{x}$ & \\
\hline BCF & $\mathrm{x}$ & & & $\mathrm{x}$ & & \\
\hline BCFzip & $\mathrm{x}$ & & & $\mathrm{x}$ & & \\
\hline gbXML & $\mathrm{x}$ & & & & & \\
\hline Cobie & & & & & $\mathrm{x}$ & \\
\hline
\end{tabular}

\begin{tabular}{|c|c|c|c|c|c|c|}
\hline \multicolumn{7}{|l|}{ Usability } \\
\hline Clear interface & & $\mathrm{x}$ & $\mathrm{x}$ & $\mathrm{x}$ & $\mathrm{X}$ & $\mathrm{X}$ \\
\hline Simple navigation & $\mathrm{X}$ & $\mathrm{x}$ & $\mathrm{x}$ & $\mathrm{x}$ & $\mathrm{x}$ & $\mathrm{x}$ \\
\hline Easy to use & $\mathrm{x}$ & $\mathrm{x}$ & $\mathrm{x}$ & $\mathrm{x}$ & $\mathrm{x}$ & $\mathrm{x}$ \\
\hline
\end{tabular}

Based on Table 1, the most suitable viewer is Tekla BIMsight, nonetheless in addition with this viewer and because of its ability to compare models will be 
selected BIM Vision too to make the comparison between model versions allowing to identify the changes in the model.

\subsection{Proposing a workflow}

Figure 1 introduces the proposed workflow using Tekla BIMsight, BIM Vision, Solibri IFC Optimizer, and BCFier. In this workflow has been considered two stages:

a) Design and coordination

- $\quad$ Modelling: each designer develops their own models to be shared as IFC files in a server.

- Optimization: the architect uses Solibri IFC Optimizer to reduce the size files up to $80-95 \%$ and the file is compressed to IFCzip format.

- $\quad$ Federated model: once the files are optimised, the architect will use Tekla BIMsight to integrate each IFCzip file in a federated model. This model will used to run clash detection and to check visually any error between models. These errors will be registered in a BCF file produced by Tekla BIMsight and shared with the owner via server.

- $\quad$ Feedback: the client will use BCFier to read the BCF file with comments made by the architect, then the client will use the same software to reply those comments. The BCF file with the client comments will be shared in the server.

- Coordinating design/comments: the designers will read the BCF file with the client replies using Tekla BIMsight and they will discuss the feasibility to make the changes indicated by the client.

b) Updating

- Modelling: with the feedback from the client and being agreed the likely solutions to any problem, each designer will modify their own native files, export it to IFC format and share it via server.

- $\quad$ Checking changes: the architect will take the new models and compare them with the old ones using BIM Vision. This software just read IFC files, then it is not possible to optimise the files and transform them in this step, then to avoid interoperability issues this optimisation will be done after checking the changes in the model.

- Optimisation: the new files are optimised using Solibri IFC Optimizer and converted to IFCzip format. These new files will be used to replace the old versions in the federated model. 


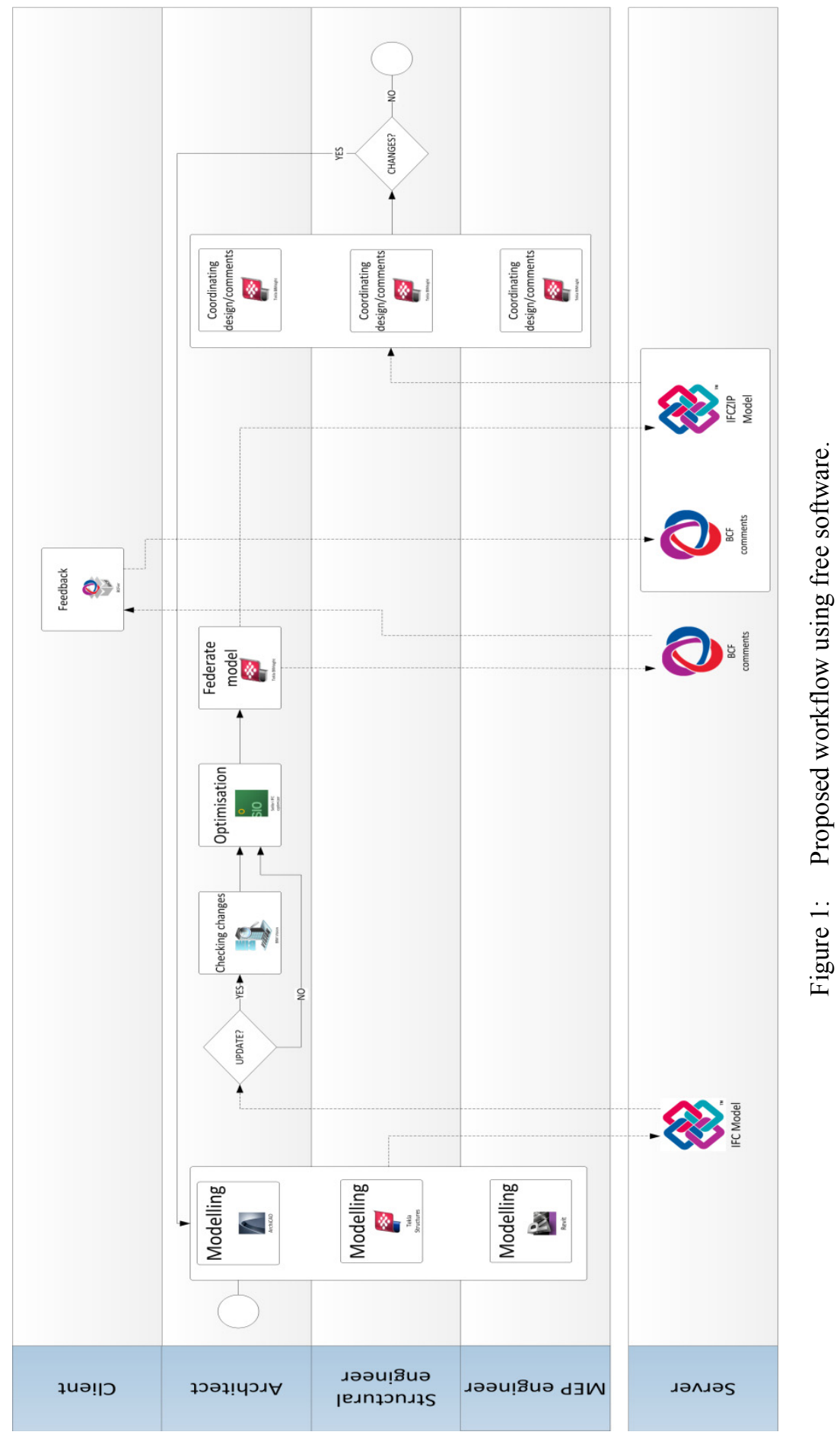




\section{Conclusions}

The SMEs need to face on important barriers to implement BIM, like high initial investment and staff training, nevertheless the software discussed is free and simple to use, even though will be need a modelling software to create the models at least the free software will facilitate the coordination and communication process. With a minimal training and without invest in software any actor will be able to be involved in the coordination of specialities.

About the software analysed is possible to state that some of them are very good. Tekla BIMsight could replace the commercial version of Navisworks Manage for coordination and clash detection of specialities during the design stage. Also is important highlight the feature that BIM Vision has that will allow having a better control every time a model is updated, making possible to know which parts have been modified.

Respect to the proposed workflow, the software have been put through the coordination process to follow the information workflow and avoid interoperability issues like could happen if the IFC file is optimised to IFCzip before run the comparison process in BIM Vision. To include latest software in the work-flow had been important to bring control in the process, then the architect will run a command into the software to identify the changes made for each designer.

Even though the workflow had been well defined, it still can be improved creating a server to define content management and data security avoiding that any actor can modify data without permission. However future researches should consider creating a low cost server to support the proposed workflow from this research.

\section{References}

[1] Hartmann, T. \& Fischer, M. Applications of BIM and Hurdles for Widespread Adoption of BIM. eConstruction Roundtable Event Report, Stanford University, 2008.

[2] Eastman, C., Teicholz, P., Sacks, R. \& Liston, K. BIM Handbook: A guide to Building Information Modeling for owners, managers, designers, engineers, and contractors ( $2^{\text {nd }}$ edition), John Wiley \& Sons, Inc.: New Jersey, 2011.

[3] Deutsch, R. BIM and Integrated Design: Strategies for Architectural Practice, John Wiley \& Sons, Inc.: New Jersey, 2011.

[4] Elvin, G. Integrated Practice in Architecture, John Wiley \& Sons, Inc.: New Jersey, 2007.

[5] National Building Standards (NBS), National BIM Report, 2015.

[6] Computer Integrated Construction Research Program (CIC), BIM Planning guide for facility owners, 2012.

[7] Pramod, K. BIM for building owners and developer, John Wiley \& Sons, Inc.: New Jersey, 2012. 
[8] Kymmell, W. Building information modelling: Planning and managing construction projects with $4 D$ and simulations. The McGraw-Hill Companies, Inc., 2008.

[9] Smith, D. and Tardif, M. Building Information Modeling: A Strategic Implementation Guide for Architects, Engineers, Constructors, and Real Estate Asset Managers. New Jersey: John Wiley \& Sons, Inc., 2009.

[10] Becerik, B. Suggestions for improving adoption of online collaboration and project management technology. Association of Researchers in Construction Management, 20th Annual ARCOM Conference. Khosrowshahi, F (Ed.), Heriot Watt University, Vol. 2, pp. 1221-1233. 2004.

[11] European Commission. The new SME definition: user guide and model declaration. Enterprise and industry publications, 2005.

[12] BIM and the SMEs: Opportunity is knocking, https:/www.adjacentgovernment.co.uk/pbc-edition-004/bim-and-thesmes/

[13] Klaschka, R. BIM in Small Practices: Illustrated Case Studies. Newcastle upon Tyne NBS, 2014.

[14] Kavanagh, P. Open source software: Implementation and management. United States of America: Elsevier Digital Press, 2004.

[15] Muffatto, M. Open source: a multidisciplinary approach. London: Imperial College Press, 2006. 